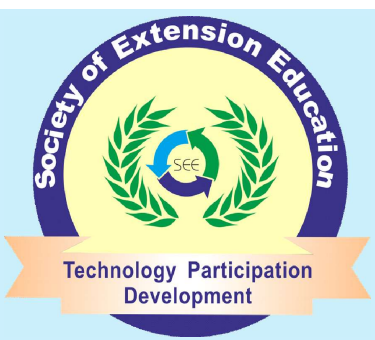

Research Article

\section{Indian Research Journal of Extension Education}

ISSN: 0972-2181 (Print), 0976-1071 (Online)

NAAS Rating : 5.22

Journal homepage: seea.org.in

https://doi.org/10.54986/irjee/2022/jan_mar/50-54

\title{
Effectiveness of the Multimedia Training Module on Farmer's Knowledge in using Bio-control Agents : An Experimental Investigation
}

\author{
Rewendra Kumar Sahu', M.L. Sharma ${ }^{2}$, P. Mooventhan ${ }^{3}$ and M.A. Khan ${ }^{4}$
}

1.Young Professional- II (Agril .Ext.), 3.Scientist, ICAR-NIBSM, Baronda, Raipur, Chhattisgarh, India. 2.Prof. \& Head, 4.Prof., Department of Agril .Ext., COA, IGKV, Raipur, Chhattisgarh, India.

Corresponding author e-mail : rewendrasahu@gmail.com

Paper Received on August 31, 2021, Accepted on November 02, 2021 and Published Online on January 01, 2022

\begin{abstract}
The present study aims to analyze the effectiveness of the multimedia training modules in terms of knowledge gain among bio-control user's farmers. The study was purposively conducted in Chhattisgarh where, a total of 200 biocontrol user's farmers were selected randomly and divide into eight groups equally. Bio-control agents was selected as farm technology based on new and need based one. The Barsch learning style inventory was used to access the learning style of farmers and results showed that majority (67.67\%) of them were preferred visual learning style. The knowledge was assessed through in-build knowledge test on the specific aspects. From the result, at Dhamtari district, the Group-I (Katalboard) has highest (144.37\%) knowledge gain and in Raipur district Group-V (Baronda) has lowest (37.60\%) knowledge gain. The overall knowledge gain ranges from 37.60 per cent to 144.37 per cent in the study area; this variation indicated that the farmers having different level of knowledge aspects in the biocontrol agents. There was also statistically significant gain in knowledge (t-test 23.91) from pre to post exposure mean scores which can be interpreted that the multimedia training module had significant effect on the knowledge gain on bio-control agents farming practices. The results of the study clearly indicate the importance of multimedia training modules in transfer of knowledge and skill on scientific farming practices.
\end{abstract}

Keywords: Bio-control agents; Multimedia training module; Knowledge gain; ICT tools.

$\mathbf{E}_{\text {ffective farm communication interventions are }}$ an important means of providing continuous learning situations to farmers so that they can develop a better understanding of the application of scientific farming practices. The recent developments in the field of communication media and technologies can possibly provide information to farmers in an effective, efficient, instant, interactive and in a participatory manner (Singh et al. 2003). The ICTs provide better scope for the creation of new and efficient technology transfer systems for the betterment of rural communication and its application provides new tools for improving access to information. Among the various ICT tools, multimedia plays an imperative source in the dissemination of scientific technologies to bridge the knowledge gap of rural farmers. The audio-visual component in this technology helps in the dissemination of knowledge to the farming community in an interesting and coherent manner. The interactive features and user-friendliness of multimedia modules facilitate better maneuverability, 
easy information retrieval and storage and could attract a large number of the audience (Vidya and Manivannan 2010). The quality and applicability of thus prepared multimedia modules on knowledge gain among bio-control agents user's farmers remained untouched. Keeping this in view, the present study was undertaken with an objective to measure the knowledge gained and skill acquisition by the bio-control agent's user's farmers through multimedia modules on biocontrol agent's users farming.

Bio-control is a method of controlling pest i.e. insects, mites, weeds and plant disease causing organism by using other biological agents like, bacteria, viruses, fungi, insects and other microbes. They are the natural enemies like parasites, predators and other mechanisms for controlling plant pests. The biological control agent helps in keeping up and adjusting the plant species alongside their natural enemies.

\section{METHODOLOGY}

The study was carried out in four districts (Raipur, Durg, Dhamtari and Rajnandgaon) of Chhattisgarh plains region during the years 2017 to 2019 . Two villages from each selected district were identified purposively. In this way a total eight villages $(2 \times 4=8)$ were selected and 25 farmers were selected purposively from each selected village, in this way a total of 200 farmers (Total $25 \times 8=200$ ) were selected for the investigation. This research employs one group before after experimental design where the respondents were randomly assigned to groups.

The multimedia modules were developed based on the prioritized needs of the Bio-control agent's user's farmers in an easy, understandable and local language (Hindi) in Audio-visual formats. Based on farmer's prioritization and expert's suggestions, seven identified multimedia modules such as Introduction about biocontrol agents, Seed treatment with Trichoderma, Installation of pheromone trap, NPV (Nuclear Polyhedrosis Virus), Tricho Card, Soil treatment by Trichoderma, Nursery treatment by Pseudomonas. The data was collected through structured interview schedule to assess their knowledge gain and skill.

The knowledge of the respondents was measured on two occasions before intervention and fifteen days after intervention to multimedia training module. For that purpose, forty items were constructed with the help of difficulty and discrimination index. Each correct answer was given one score and wrong answer zero. This will indicate the farmer's knowledge on the subject matter before being exposed to multimedia instruction on biocontrol agents. This test is called pre-exposure knowledge test. On the completion of pre-exposure knowledge test, the multimedia instruction (educational video) on bio-control agents was demonstrated to the farmers for learning. After viewing the multimedia instruction, farmers were exposed to the developed knowledge test which covers all the subject matter contents of multimedia instruction after fifteen days gap. At the end of the programme, the farmers were requested to answer for all the 40 items developed for knowledge test on the bio-control agents. The maximum attainable knowledge score was 40. After end of this test, the knowledge gain of the farmers using bio-control agents was assessed. The difference in the knowledge levels of pre-exposure and post exposure was taken as knowledge gained by each respondent.

$\mathrm{DI}^{\text {ith }}$ question $=\frac{\text { No. of correct response for ith question }}{\text { Total No. of respodents }}$

$$
\text { Discrimination index }=\frac{\left(\mathrm{n}^{1 \mathrm{H}}-\mathrm{n}^{2 \mathrm{~L}}\right.}{\mathrm{n}}
$$

Where,

DI=Difficult index

$\mathrm{n}^{\mathrm{HH}}=$ Number of non-sample respondents in 25 per cent high group who answered correctly

$\mathrm{n}^{2 \mathrm{~L}}=$ Number of non-sample respondents in 25 per cent low group who answered correctly and

$\mathrm{n}=\quad\left(\mathrm{n}^{1}+\mathrm{n}^{2}\right)=$ Total number of non-sample respondents in 25 per cent high group and 25 per cent low group.

The statistical tools used to include frequencies and percentages, arithmetic mean, standard deviation and paired t-test. The data were analyzed using SPSS.

\section{RESULTS AND DISCUSSION}

Knowledge is the crucial component that plays a vital role in the behavior of an individual. The dissemination of knowledge or scientific information among farmers will play a greater role in adoption of scientific farming practices. Keeping this in view, the knowledge gain of respondents before exposure and after 15 days of exposure to multimedia training modules was assessed. The effectiveness of the multimedia training module on farmer's knowledge in using biocontrol agents is presented in Table 1 . 
Table 1. Distribution of respondents according to village wise, mean difference and percentage change in knowledge gain from multimedia training module ( $N=200$ (25 for each group)

\begin{tabular}{|c|c|c|c|c|c|c|}
\hline \multirow{2}{*}{$\begin{array}{l}\text { Name of the } \\
\text { districts }\end{array}$} & \multirow{2}{*}{$\begin{array}{l}\text { Group/ } \\
\text { villages }\end{array}$} & \multicolumn{2}{|c|}{ Mean knowledge } & \multicolumn{2}{|c|}{ Knowledge gain } & \multirow{2}{*}{$\begin{array}{c}\text { Paired } \\
\text { t-test }\end{array}$} \\
\hline & & Pre-test & Post-test & Mean-differ. & $\%$ change & \\
\hline \multirow[t]{3}{*}{ Dhamtari } & Group-I: Katalboard & 12.08 & 29.52 & 17.44 & 144.37 & $4.65 * *$ \\
\hline & Group- II: Hatband & 14.48 & 26.20 & 11.72 & 80.94 & $1.57 * *$ \\
\hline & Total & & & & 112.65 & \\
\hline \multirow[t]{3}{*}{ Durg } & Group- III: Arasnara & 21.92 & 31.48 & 9.56 & 43.61 & $10.67 * *$ \\
\hline & Group-IV: Chicha & 16.92 & 26.52 & 9.60 & 56.74 & $10.80 * *$ \\
\hline & Total & & & & 50.17 & \\
\hline \multirow[t]{3}{*}{ Raipur } & Group- V: Baronda & 15.32 & 21.08 & 5.76 & 37.60 & $6.55 * *$ \\
\hline & Group-VI: Adsena & 17.12 & 24.04 & 6.92 & 40.42 & $11.43 * *$ \\
\hline & Total & & & & 39.01 & \\
\hline \multirow[t]{3}{*}{ Rajnandgaon } & Group- VII: Sonesarar & 15.52 & 22.12 & 6.60 & 42.52 & $11.67 * *$ \\
\hline & Group- VIII: Kirgi & 16.48 & 23.48 & 7.00 & 42.47 & $12.92 * *$ \\
\hline & Total & & & & 42.49 & \\
\hline
\end{tabular}

**Significant at $1 \%$ level $(\mathrm{p}<0.01)$

Group/village wise knowledge gain : For improved cultivation, gaining as much knowledge as possible is important. Knowledge does not pertain to science and technology and the fields we study in books. Knowledge is also very important to shape our personality and perfect our behavior and dealings with people.

It is apparent from Table 1 that all the groups (Group I to Group VIII) had shown effective knowledge gain by multimedia training module. From the result, at Dhamtari district, the Group-I (Katalboard) has highest (144.37\%) knowledge gain followed by Group-II (Hatband) 80.94 per cent. From Durg district, the GroupIV (Chicha) has maximum (56.74\%) knowledge gain followed by Group-III (Arasnara) 43.61 per cent. From
Rajnandgaon district the Group-VIII (Kirgi) has higher $(42.47 \%)$ knowledge gain followed by Group-VII (Sonesarar) 42.52 per cent and from Raipur district Group-VI (Adsena) has highest (40.42\%) knowledge gain followed by Group-V (Baronda) 37.60 per cent. Among the eight groups, two groups namely Group-I and Group-II from Dhamtari district has significant highest percentage change in knowledge gain even though farmers from these villages have scored low mean pre-knowledge score. It might be due to the fact of multimedia training module and higher experiences in using bio-control agents. Moreover the highly significant 't' values once again confirm statistically, the considerable knowledge gain among the farmers due to

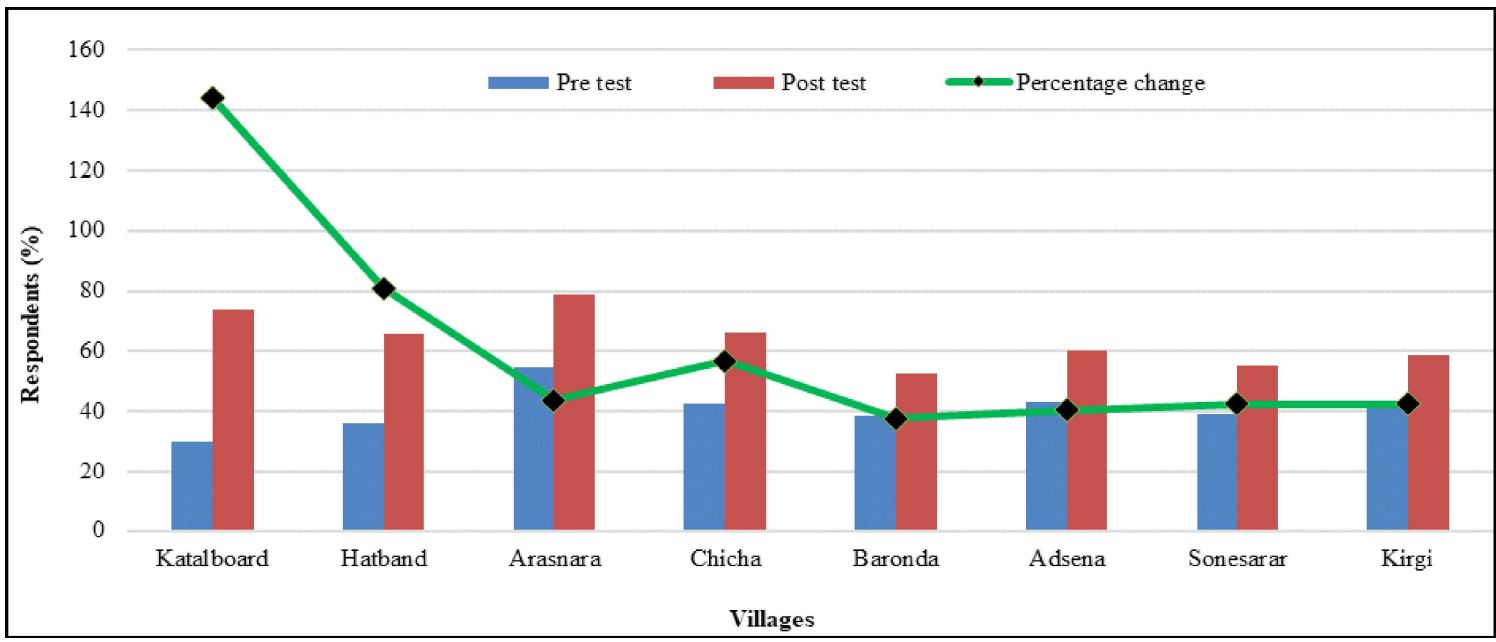

Fig.1: Distribution of respondents according to village wise, mean difference and percentage change in knowledge gain from multimedia training module 
the treatment. Further, it is interesting to note that the knowledge gain has direct and positive relationship with the visual learning style of the farmers using bio-control agents. This learning ultimately resulted in the significant knowledge gain. The overall knowledge gain ranges from 37.60 per cent to 144.37 per cent in the study area; this variation indicated that the farmers having different level of knowledge aspects in the bio-control agents (Fig. 1).

The findings of the study are in conformity with the results reported by Mooventhan (2016) and Anandaraja (2002).

Knowledge gain from multimedia training module : The use of multimedia to enhances teaching and learning complements traditional approaches to learning. Effective instruction builds bridges between farmer's knowledge and the learning objectives of the course. Using multimedia engages farmers, aids farmer's retention of knowledge, motivates interest in the subject matter and illustrates the relevance of many concepts.

Table 2. Knowledge gain from multimedia training module $(\mathrm{N}=\mathbf{2 0 0})$

\begin{tabular}{lcc}
\hline Farmers using bio-control agents & Mean & SD \\
\hline Pre knowledge test & 16.23 & 5.07 \\
Post knowledge test & 25.55 & 5.99 \\
Mean Difference & \multicolumn{2}{c}{9.32} \\
Percentage change & \multicolumn{2}{c}{57.42} \\
t- test & $23.91^{* *}$ \\
\hline
\end{tabular}

** Significant at $1 \%$ level $(\mathrm{p}<0.01)$,

It is resulted from Table 2 that overall percentage change of respondents from pre to post knowledge test were 57.42 per cent and mean difference were 9.32. The results indicate that the gain in knowledge with regards to bio-control agents is significant at 01 per cent levels of probability $(t=23.91, \mathrm{p}<0.01)$. The difference observed between the mean scores of knowledge level of respondents in pre and post-exposure stages was found to be statistically significant and we might say that the multimedia training module significantly increased the knowledge of the participants. Gender wise knowledge gain : The assessment of preferred learning styles of farmers using bio-control agents to determine if males and females have similar learning styles. With this information it may assist in the development and implementation of gender-specific training approaches that would maximize farmer's motivation and learning by tailoring instruction to gender specific needs of respondents. To achieve these aims, we comparatively analyze male and female farmers and we found that 25.38 per cent difference in percentage change and 4.12 in their mean differences in their knowledge gain. Using t-test found that the data is highly significant at 1 per cent level of significance.

Table 3. Gender wise knowledge gain from multimedia training module

\begin{tabular}{lcccc}
\hline \multirow{2}{*}{ Gender } & \multicolumn{2}{c}{ Mean knowledge } & \multicolumn{2}{c}{ Knowledge gain } \\
& Pre-test & Post-test & Mean diff. & \% change \\
\hline Male $(\mathrm{n}=126)$ & 16.23 & 27.08 & 10.85 & 66.85 \\
Female (n=74) & 16.23 & 22.96 & 6.73 & 41.47 \\
Mean difference & \multicolumn{2}{c}{4.12} & \\
Percentage change & \multicolumn{2}{c}{25.38} \\
Difference (t-test) & \multicolumn{2}{c}{$6.210^{* *}$} \\
\hline
\end{tabular}

**Significant at $1 \%$ level $(\mathrm{p}<0.01)$

Thus, male and female respondents have significantly different learning styles in comparison to knowledge gain. The results obtained from the learning style points in Table 3, that the trend of learners' learning styles was vary for male and female farmers. This tendency will affect learning outcomes. Therefore, it is necessary for the trainer to know the trend of male and female communities differently for enhance the knowledge of male and female farmers. If multimedia media is developed should consider the needs of farmers in terms of the trend of learning styles. One of strategies that can be done is to combine audio and visual into a single unit in a media, so that individuals can maximize their knowledge acquisition.

Level of knowledge gain: The knowledge level of the farmers was measured with the help of a knowledge index. Various aspects of bio-control agents were taken in to consideration, viz., soil, seed, nursery and seedling treatment with Trichoderma, placing of Tricho-card, assembling and installation of pheromone trap, foliar spray of pseudomonas mass production of NPV by farmer etc.

Table 4. Distribution of respondents according to their overall level of knowledge gain $(\mathbf{N}=\mathbf{2 0 0})$

\begin{tabular}{lll}
\hline Level of knowledge gain & No. & $\%$ \\
\hline Low (Up to 33.33\%) & 59 & 29.50 \\
Medium $(33.34-66.66 \%)$ & 68 & 34.00 \\
High (Above $66.67 \%)$ & 73 & 36.50 \\
Total & 200 & 100 \\
\hline
\end{tabular}

The knowledge of respondents on these aspects 
was collected before and after delivering the multimedia training module on bio-control agents. The findings of the study have been presented in Table 4 .

The study revealed that before intervention of multimedia training module on farmers using bio-control agents, majority of the farmers had medium-to-low levels of knowledge. But, after the intervention of multimedia training module on bio-control agents, considerable number of respondents moved from medium to high category and similarly from low to medium category. It is apparent from the data that 36.50 per cent of respondents were under the high-level knowledge gain followed by more than one-third (34.00\%) per cent respondents were medium level and 29.50 per cent respondents had low level of knowledge gain.

Total 63.50 per cent of respondents were fall in low and medium level category because there also exists a large gap between the availability of knowledge and its effective application in decision making. The knowledge that is available is largely disciplinary which makes it often difficult to apply in a wider socio-economic and interdisciplinary context. The knowledge available is also commonly perceived to be hypothetical and theoretical instead of focusing on the needs of end users with the aim of facilitating action and/or social change. The end users thus find it difficult to use such knowledge. However, there is an increasing awareness about the importance of research approaches that employ new ways to organize and manage research in bio-control agents. Such a step would help to improve the relevance of research and would also enhance knowledge adoption by the end users.

\section{CONCLUSION}

There was statistically significant gain in knowledge from pre-test mean scores to post-test mean scores which can be interpreted that the multimedia modules were highly effective in enhancing the knowledge level of farmers using Bio-control agents on various farming practices and this increase might be due to learning through hearing, seeing and understanding of multimedia training modules. In proving that axiom one picture worth a thousand words seeing the pictures makes the information clearer and complete which helps in creating lasting impressions on the minds of farmers. Hence, efforts may be taken up by the extension personnel to disseminate knowledge on scientific farming practices by using information and communication technology tools especially multimedia training modules to educate farmers and thereby maximizing their profit. Thus, it can be stated that multimedia training modules not only facilitate the increased knowledge of the viewers but also assists in the retention of the knowledge gained.

\section{ACKNOWLEDGEMENT}

The authors are grateful to the Indira Gandhi Krishi Vishwavidyalaya (IGKV), Raipur National Institute of Biotic Stresses Management (ICAR- NIBSM), Raipur and University Grant Commission (UGC), New Delhi for providing the necessary facilities and financial support for completion of this study.

\section{CONFLICTS OF INTEREST}

The authors declare that they have no conflicts of interest.

\section{REFERENCES}

Anandaraja, N. (2002). Developing farmer friendly interactive multimedia compact disc and testing its effectiveness in transfer of farm technology. Ph.D. Thesis, TNAU, Coimbatore.

Mooventhan, P. (2016). Empowerment of tribal farmers for good dairy farming practices through multimedia approach, Ph.D. Thesis, NDRI, Karnal, Haryana, India.

Singh, J.; Chahal, V.P. and Vidyubata. (2003). Media use profile of farmers in Haryana. Indian J of Ext. Edu., 39 (3\&4): 147-253.

Vidya, P. and Manivannan, C., 2010. Development of an educational interactive video-DVD on dairy health management practices. Intl. J. Edu. and Devel. Info. and Comm. Tech., 6 (1): 30-39. 